$11^{2} / a^{8} \quad$ Hh. 213 ORNL/TM-6363

\title{
Simulation of Multispecies Impurity Transport in Tokamaks
}

\author{
T. Amano \\ E. C. Crume
}

\section{MASTER}

OAK RIDGE NATIONAL LABORATORY OPERATED BY UNION CARBIDE CORPORATION · FOR THE DEPARTMENT OF ENERGY 


\section{DISCLAIMER}

This report was prepared as an account of work sponsored by an agency of the United States Government. Neither the United States Government nor any agency Thereof, nor any of their employees, makes any warranty, express or implied, or assumes any legal liability or responsibility for the accuracy, completeness, or usefulness of any information, apparatus, product, or process disclosed, or represents that its use would not infringe privately owned rights. Reference herein to any specific commercial product, process, or service by trade name, trademark, manufacturer, or otherwise does not necessarily constitute or imply its endorsement, recommendation, or favoring by the United States Government or any agency thereof. The views and opinions of authors expressed herein do not necessarily state or reflect those of the United States Government or any agency thereof. 


\section{DISCLAIMER}

Portions of this document may be illegible in electronic image products. Images are produced from the best available original document. 
Printed in the United States of America. Available from National Technical Information Service

U.S. Department of Commerce

5285 Port Royal Road, Springfield, Virginia 22161

Price: Printed Copy $\$ 4.50$; Microfiche $\$ 3.00$

This report was prepared as an account of work sponsored by an agency of the United States Government. Neither the United States Government nor any agency thereof, nor any of their employees, contractors, subcontractors, or their employees, makes any warranty, express or implied, nor assumes any legal liability or responsibility for any third party's use or the results of such use of any information, apparatus, product or process disclosed in this report, nor represents that its use by such third party would not infringe privately owned rights. 
ORNL/TM-6363

Dist. Category UC-20g

Contract No. W-7405-eng-26

FUSION ENERGY DIVISION

SIMULATION OF MULTISPECIES IMPURITY

TRANSPORT IN TOKAMAKS

T. Amano

On leave from Osaka University, Japan

and

E. C. Crume

Date Published - June, 1978

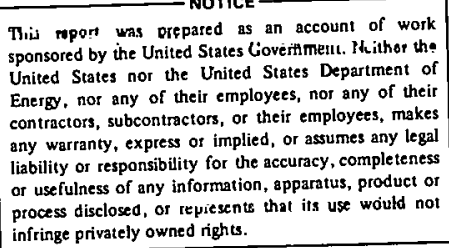

This noprt was prepased as an account of work sponsored by the United States lioverithertll. Nkithor the United States nor the United States Department of

Enersy, nor any of their employees, nor any of their

constores, makes

any warranty, express or implied, or assumes any legal

livility or responsibitity for the accuracy, completeness

ar usefulness of any information, apparatus, product or

of usefulness of any inferesents that irs use would not

infringe privately owned rights.

infringe

Prepared by the

OAK RIDGE NATIONAL LABORATORY

Oak Ridge, Tennessee 37830

operated by

UNION CARBIDE CORPORATION

for the

DEPARTMENT OF ENERGY 


\section{THIS PAGE}

\section{WAS INTENTIONALLY \\ LEFT BLANK}


SIMULATION OF MULTISPECIES IMPURITY TRANSPORT IN TOKAMAKS

T. AMANO, ${ }^{*}$ E. C. CRUME

Fusion Energy Division

Oak Ridge National Laboratory

Oak Ridge, Tennessee, UŚA 37830

\begin{abstract}
ABS'IRACT
To simulate multispecies impurity transport in tokamaks, a set of coupled continuity equations including source and sink terms from atomic processes (rate terms) were solved numerically. The diffusion and rate terms are integrated separately in time using a fractional step-splitting technique which is accurate to second order in the time step. The rate terms are integrated using an eigenvalue method which allows such a large time step that diffusion constrains the step size. For the diffusion coefficients, approximate forms of the Pfirsch-Schlüter coefficients calculated by Hirshman were generally used (to save computer time), but the exact forms were used for certain comparisons. Anomalous diffusion was treated using a pseudoclassical diffusion coefficient. Calculations were performed treating individually all the ionization stages of oxygen and iron impurities in a hydrogen plasma. Calculated $U$ VI and $O$ VII relative density profiles agree qualitatively with profiles measured in the Adiabatic Toroidal Compressor (ATC) tokamak when purely neoclassical diffuaion coeffirients are used. Because the calculated

* On leave from Osaka University, Japan.
\end{abstract}


profiles are also very sensitive to the magnitude of the neutral oxygen influx and atomic process rate coefficients, it is difficult to separate the diffusion and the atomic physics problems. The calculated Fe XV relative density profile is much less sensitive to the neutral iron influx although it also is sensitive to the rate coefficients. A model in which pseudoclassical diffusion coexists with neoclassical gives nearly as good agreement with experiment as one with only neoclassical. Better resolution of this problem requires coordinated measurements of absolute intensities of impurity spectra and radial profiles, Hinng with other plasma parameters such as the electron density and temperature profiles, and the ion temperature profile. Additionally, measurements of impurity source parameters such as the neutral energy or energy distribution are needed.

\section{INTRODUCTION}

The development of tokamaks into efficient fusion reactors will be seriously impeded, if not preventê, unleco tokainak plasmás can be maintained relatively impurity free. Consequently, much theoretical [1] and experimental [2] effort is being expended in attempts to understand impurity behavior in tokamak plasmas. We describe the use of an impurily transport simulation code to model the transport of oxygen and iron impurities as measured in experiments in the ATC tokamak. The code employs the corona atomir. physics modcl. Neuclassical transport for all ion species, including both density gradient and temperature gradient cffects, is used. However, because such transport is primarily inward, anomalous outward transpurt, according to different models, is used to supplement the neoclassical transport to treat impurity recycling. By impurity recycling we 
mean the maintenance of a steady state by an inward flux of neutral impurities, perhaps from a wall source, balancing the outward flux of charged particles at the plasma edge. Among the novel features of the calculations are the inclusion of the complete neoclassical particle transport model, the attempts to reproduce the measured impurity density profiles in a self-consistent manner, and the technique employed to solve the coupled continuity equations for all plasma ion species.

This code is an appreciable improvement and extension of an earlier code [3]. As described in Section 2, the code solves the coupled continuity equations for a set of plasma ions, here hydrogen plus several charge states of one or more impurity elements. Except for the hydrogen ions, each equation contains electron impact ionization and recombination terms appropriate to the corona model assumption [4] in addition to the diffusion term. In order to concentrate on particle transport, neither diffusion of the plasma current nor energy flow is treated; rather the plasma current and temperature profiles are specified externally. Although these profiles remain fixed for modeling plasma conditions in the steady current state portion of a tokamak discharge, transient current and temperature conditions can be modeled using interpolation among profiles characteristic of different times in the transient portions of the discharge. The neoclassical transport coefficients used for the iun transport are the P[irsch-Schlüter rnefficients calculated by Hirshman [5] for an arbitrary number of plasma species. The expressions for these coefficients are complicated enough that a separate computer subroutine [6] is needed to evaluate them. However, the amount of computer time required to calculate these cnefficients every time step may become undesirably large, espectally for 
preliminary investigations when there are many ions. For these investigations we use approximate expressions derived from those given by Rutherford et a1. [7] as discussed in Section 2 .

In Section 3 we describe our modeling of oxygen and iron impurity diffusion and compare calculated profiles of line radiation from $O V I$, $O$ VII, and Fe XV with profiles measured [8] in the ATC tokamak. The atomic rate coefficients used are discussed in this section. The conclusions are summarized in Section 4.

\section{THE COUPLED ION CONTINUITY EQUATIONS AND THEIR NUMERICAL SOLUTION} We consider a hydrogen plasma containing oxygen and iron impurities. The flux-surface averaged continuity equation for a $k$ times ionized impurity element I having density $n_{I}^{k}$ can be written,

$\partial_{t} n_{I}^{k}=n_{e}\left[s_{I}^{k-1} n_{I}^{k-1}-\left(s_{I}^{k}+\alpha_{I}^{k}\right) n_{I}^{k}+\alpha_{I}^{k+1} n_{I}^{k+1}\right]-\frac{\left(\partial_{r} r \Gamma_{I}^{k}\right)}{r}$

where for oxygen, $k=1,2, . . ., 8$, and for iron, $k=1,2, . ., 26$. Tn low plasma $\beta$ approximations in which the cross sections of the flux surfaces are concentric circles, $r$ represents the minor radial coordinate of the toroidal tokamak plasma. Here $\Gamma_{I}^{k}$ is the radial diffusion flux, $n_{e}$ is the electron density, $S_{I}^{k}$ is the rate coefficient for ionization out of the charge state $z_{k}$ into the charge state $z_{k}+1=z_{k+1}$, and $\alpha_{I}^{k}$ is the rate coefficient for recombination (radiative plus dielectronic) out of the charge state $z_{k}$ into the charge state $z_{k}-1=z_{k-1}$. We do not treat neutral hydrogen, and so the continuity equation for hydrogen takes the simple form,

$\partial_{t} n_{H}=-\frac{\left(\partial_{r} r \Gamma_{H}\right)}{r}$ 
Hirshman's [5] expression for the particle flux of the plasma species with density $\mathrm{n}_{I}$, temperature $\mathrm{T}_{I}$, and charge state $\mathrm{Z}_{I}$ interacting with an arbitrary number of other plasma species, $J$, can be written in the large aspect ratio, low plasma $\beta$ approximation as.

$\Gamma_{I}=\frac{-q^{2} \rho_{I}^{2} n_{I}}{\tau_{I I}} \sum_{J}\left[C_{1}^{I J} \partial_{r} \ln n_{J}+\left(C_{I I}^{I J}+c_{12}^{I J}\right) \partial_{r} \ln T_{J}\right]$

where $q$ is the safety factor, $\rho_{I}$ is the thermal toroidal gyroradius of species I,

$\rho_{I}^{2}=\left(\frac{2 \mathrm{~T}_{\mathrm{I}}}{\mathrm{m}_{\mathrm{I}}}\right) /\left(\frac{\mathrm{z}_{\mathrm{I}}^{2} \mathrm{e}^{2} \mathrm{~B}_{\mathrm{T}}^{2}}{\mathrm{~m}_{\mathrm{I}}^{2} \mathrm{c}^{2}}\right)$

where $B_{T}$ is the toroidal magnetic field, and $\tau_{I J}$ is a collision time,

$\tau_{I J}^{-\frac{1}{J}}=\frac{4(2 \pi)^{1 / 2} n_{J}\left(z_{I} Z_{J}\right)^{2} e^{4} \ln \Lambda_{I J}}{3\left(m_{I} T_{I}^{3}\right)^{1 / 2}}$

Henceforth we will. suppress the superscripts which indicate the charge state except where clarity may suffer. Hirshman glves expressions for transport coefficients $\mathrm{L}_{\mathrm{mn}}^{\mathrm{IJ}}$ to which the $\mathrm{C}_{\mathrm{mn}}^{\mathrm{IJ}}$ are related by

$\mathrm{C}_{\mathrm{mn}}^{\mathrm{IJ}}=\left(\frac{\tau_{\mathrm{II}}}{2 \delta^{2} \mathrm{R}^{2} \mathrm{~m}_{\mathrm{I}} \mathrm{n}_{\mathrm{I}}}\right)\left(\frac{\mathrm{Z}_{\mathrm{I}} \mathrm{T}_{\mathrm{J}}}{\mathrm{Z}_{\mathrm{J}} \mathrm{T}_{\mathrm{I}}}\right) \mathrm{L}_{\mathrm{mn}}^{\mathrm{IJ}}$

where $S$ is the inverse aspect ratio and $R$ is the tokamak major radius. In the general case the expressions for $\mathrm{L}_{\mathrm{mn}}^{\mathrm{IJ}}$ are very complicated and 
need a separate computer subroutine for evaluation [6]. Hirshman [5] has provided some approximate relations for special cases, but these also are rather complicated especially when the temperatures of the various species are strongly equilibrated. Rutherford et al. [7], taking all ion species to have a common temperature, have simplified Hirshman's approximations into forms more suitable for transport simulations using the Lorentz approximation for opecies of different mass, and a leading term approxlmation for interactions between species of the same mass but different charge states. We have combincd the expressions of Ref. [6] to describe particle transport in a plasma containing an arbitrary number of charged species and obtain for the $\mathrm{C}_{\mathrm{mn}}^{\mathrm{IJ}}$,

$$
\begin{aligned}
& C_{I I}^{I I}=z_{I}^{*} C_{I}^{*}\left(z_{I}^{*}\right)+(2)^{-1 / 2} \sum_{k^{\prime \neq k}} z_{I}^{k k^{\prime}}+\sum_{J<I}\left(\frac{m_{J}}{m_{I}}\right)^{I / 2} z_{I J} C_{I}^{*}\left(z_{J}^{* *}\right) \\
& C_{11}^{I J}= \begin{cases}-(2)^{-1 / 2} \tilde{z}_{I}^{k k^{\prime}}, & m_{I}=m_{J} \\
-\left(\frac{m_{J}}{m_{I}}\right)^{1 / 2} \tilde{z}_{I J} C_{l}^{*}\left(z_{J}^{*}\right), & m_{I} \gg m_{J} \\
-\tilde{z}_{I J} C_{l}^{*}\left(z_{I}^{*}\right), & m_{I} \ll m_{J}\end{cases} \\
& C_{12}^{I I} \equiv-Z_{I}^{*} C_{2}\left(Z_{I}^{*}\right) \\
& C_{12}^{I J}= \begin{cases}0.31 \sum_{k^{\prime \neq k}} z_{I}^{k k^{\prime}}, & m_{I}=\mathrm{m}_{J} \\
\left(\frac{\mathrm{m}_{\mathrm{J}}}{\mathrm{m}_{\mathrm{I}}}\right)^{1 / 2} \tilde{\mathrm{z}}_{\mathrm{IJ}} \mathrm{C}_{2}^{*}\left(\mathrm{z}_{\mathrm{J}}^{*}\right), & \mathrm{m}_{\mathrm{I}} \gg \mathrm{m}_{\mathrm{J}} \\
0, & \mathrm{~m}_{\mathrm{I}} \ll \mathrm{m}_{\mathrm{J}}\end{cases}
\end{aligned}
$$


Here,

$\mathrm{z}_{\mathrm{IJ}}=\frac{\mathrm{n}_{\mathrm{J}} \mathrm{Z}_{\mathrm{J}}^{2}}{\mathrm{n}_{\mathrm{I}} \mathrm{Z}_{\mathrm{I}}^{2}}$

$\mathrm{Z}_{\mathrm{I}}^{*}=\sum_{\mathrm{J}>\mathrm{I}} \mathrm{Z}_{\mathrm{IJ}}$

where $J>I(J<I)$ indicates a sum over species for which $m_{J}>m_{I}\left(m_{J}<m_{I}\right)$,

$\tilde{z}_{I J}=\frac{n_{J} z_{J}}{n_{I} z_{I}}$

$\mathrm{z}_{I}^{k k^{\prime}}=\frac{\mathrm{n}_{I}^{k^{\prime}}\left(z_{I}^{k^{\prime}}\right)^{2}}{n_{I}^{k}\left(z_{I}^{k}\right)^{2}}$

$\tilde{z}_{I}^{k k^{\prime}}=\frac{n_{I}^{k^{\prime}} z_{I}^{k^{\prime}}}{n_{I}^{k} z_{I}^{k}}$

and the last two expressions apply to different charge states of the same impurity element. Also,

$C_{1}^{*}(x)=\frac{0.48+0.31}{0.59+x}$

$C_{2}^{*}(x)=\frac{0.30+0.41}{0.59+x}$

We solve Eq. (1) using the numerical technique described in Ref. [3]. Equation (1) can be written schematically as

$\partial_{t} u=A u+B u$ 
where $u$ represents $n_{I}^{k}$ and $A u$ and $B u$ represent the rate and diffusion terms, respectively. Equation (10) is advanced in time according to

$u(t+\Delta t)=\exp \left(\frac{B \Delta t}{2}\right) \exp (A \Delta t) \exp \left(\frac{B \Delta t}{2}\right) u(t)$

which represents a splitting technique in which the rate and diffusion terms are stepped forward in time alternately, first the diffusion term by $\Delta t / 2$, then the rate $m$ by $\Delta t$, and then again the diffusion term by $\Delta t / 2$. Thls technique has second order accuracy in $\Delta t$, even if $A$ and $B$ do not commute. In order to avoid very short time stepe an eigenvalue method [3] is employed to solve the rate equation $\partial_{t} u=B u$. To solve the diffusion equation $\partial_{t} u=$ Au for the plasma species with density $n_{I}$ and charge state $Z_{I}$, we rewrite the diffusion equation. in the form

$\partial_{t} n_{I}=\frac{-\partial_{r} r \Gamma_{I}}{r}=\frac{\partial_{r} r\left(D \partial_{r} n_{I}+E n_{I}\right)}{r}$

where

$D=\frac{\left(q^{2}+1 / 2\right) p_{I}^{2} n_{I} C_{I I}^{I I}}{\tau_{I I}}$

$E=\frac{\left(q^{2}+1 / 2\right) \rho_{I}^{2}}{\tau}\left[\sum_{J \neq I} \hat{C}_{I 1}^{I J}{ }_{r} \ln n_{J}+\sum_{J}\left(\hat{C}_{11}^{I J}+\hat{C}_{12}^{I J}\right) \partial_{r} \ln \mathrm{T}\right]$

and $\mathrm{T}$ represents the common temperature of all plasma ion species. In F.rs (13) we have accounted approximately for the classical component of cross field diffusion, which can be nonnegligible toward the center of the plasma, by using the factor [9] $\left(q^{2}+1 / 2\right)$ instedd of $q^{2}$ alone as in Eq. (3). We have also tried to remove some of the Lorentz plasma character from the transport by using reduced masses in which it is not assumed that $\mathrm{m}_{\mathrm{I}} \gg \mathrm{m}_{\mathrm{J}}$ or $\mathrm{m}_{\mathrm{I}} \ll \mathrm{m}_{\mathrm{J}}$, and so define the $\hat{\mathrm{c}}_{\mathrm{mn}}^{\mathrm{IJ}}$, $\mathrm{I} \neq \mathrm{J}$, 
$\hat{\mathrm{C}}_{\mathrm{mn}}^{\mathrm{IJ}}= \begin{cases}\left(\frac{\mathrm{m}_{\mathrm{I}}}{\mathrm{m}_{\mathrm{I}}+\mathrm{m}_{\mathrm{J}}}\right)^{\mathrm{I} / 2} \mathrm{c}_{\mathrm{mn}}^{\mathrm{IJ}}, & \mathrm{m}_{\mathrm{I}}>\mathrm{m}_{\mathrm{J}} \\ \left(\frac{\mathrm{m}_{\mathrm{J}}}{\mathrm{m}_{\mathrm{I}}+\mathrm{m}_{\mathrm{J}}}\right)^{1 / 2} \mathrm{C}_{\mathrm{mn}}^{\mathrm{IJ}}, & \mathrm{m}_{\mathrm{I}}<\mathrm{m}_{\mathrm{J}}\end{cases}$

The set of equations of the form of Eq. (12) for all impurity species forms a tridiagonal system which is solved using standard methods. The boundary conditions imposed on Eq. (12) are

$$
\begin{aligned}
& \left(\frac{d n_{I}}{d r}\right)_{r=0, t}=0 \\
& n_{I}(a, t)=0
\end{aligned}
$$

where $\mathrm{a}$ is the minor radius of the plasma. However, application of Eq. (15b) often leads to unphysical negative impurity densities in the edge region of the plasma where the impurity density gradients can becume very steep. In an attempt to avoid this difficulty, we use a technique suggested by Post [10]. We calculate the diffusion flux a halfspatial mesh interval inside the plasma boundary, and if it becomes inward we use instead of Eq. (15b) the condition

$\Gamma_{I}\left(a-\frac{k}{2}\right)=0$

where $h$ is the spatial mesh interval. This condition prevents charged impurity ions from entering the plasma from the outside and ameliorates the negative density dfficulty. If negative densities persist after applying Eq. (16), we solve $\Gamma_{I}(r)=0$ instead of Eq. (12) over the whole region in which they occur.

To Investigatc the influence of possible anomalous contributions to the diffusion of the impurities, we write the diffusion fluxes in the form 
$\Gamma_{I}=\alpha \Gamma_{\text {In }}+\beta \Gamma_{\text {Ia }}$

where $\Gamma_{\text {In }}$ is the neoclassical flux given by Eq. (3) as modified in Eqs $(13,14)$ and $\Gamma_{I_{a}}$ is an anomalous flux defined as

$\Gamma_{I a}=-D_{e}{ }^{\partial} n_{I}$

The diffusion coefficient $D_{e}$ is a pseudoclassical electron particle diffusion coefficient of the form derived by Yoshikawa [11]

$D_{\rho}=\frac{\delta^{-2} q^{2} \rho_{e}^{2}}{\tau}$

where

$\frac{1}{\tau_{e}}=\sum_{I \neq e}\left(\frac{1}{\tau_{e I}}\right)$

This model for anomalous transport of impurities is similar to others $[6,12]$ in which the anomalous traneport of all lons, regardless of species, is described by the same diffusion coefficient. By adjusting the values of $\alpha$ and $\beta$ any combination of neoclassical and pseudoclassical diffusion can be obtained; generally, however, we treated only the purely neoclassical $(\alpha=1, \beta=0)$, purely pseudoclassical $(\alpha=0, \beta=1)$, and equally mixed $(\alpha=1, \beta=1)$ cases. When anomalous diffusion is included $(\beta=1)$, the electron density distribution is fixed in time and $n_{H}$ is calculated from the charge neutrality condition,

$\mathrm{n}_{\mathrm{H}}=\mathrm{n}_{\mathrm{e}}-\sum_{\mathrm{I}, \mathrm{k}} \mathrm{n}_{\mathrm{I}}^{\mathrm{k}}$

Neutral impurity influx, including that required for an impurity recycling model, is accounted for by taking a density distribution of the form 
$n_{I}^{o}(r)=\left[\frac{\Gamma_{I}^{o}(a)}{v_{I}^{o}}\right] \exp \left[-\left(\frac{1}{v_{I}^{o}}\right) \int_{a}^{r} d r n_{e}(r) S_{I}^{o}\right]$,

where $V_{I}^{O}$ is the thermal velocity of the neutral impurity. The neutral impurity flux at the plasma boundary is given by

$\Gamma_{I}^{o}(a)=-\gamma \sum_{k \neq 0} \Gamma_{I}^{k}(a)+\psi_{0}$

where $Y$ is the recycling coefficient and $\Psi_{0}$ is any neutral influx not related to recycling.

3. O VI, VII, AND Fe XV PROFILES IN ATC

\subsection{General}

In this section we present the results of calculations of oxygen and iron diffusion In the ATC tokamak and compare calculated and measured profiles of $\mathrm{OVI}, \mathrm{O} V I I$, and $\mathrm{Fe} X V$. Here we use the spectroscopic notation, e.g., 0 VI $\sim 0^{5+}$. I'he basic plasma parameters at the time of the measurements were taken from Ref. [13]. The electron density and temperature profiles are described by $n_{e}(r)=n_{e}(0)\left[1-(r / a)^{2}\right]$ and $T_{e}(r)=$ $\mathrm{T}_{\mathrm{e}}(0)\left[1-(\mathrm{r} / \mathrm{a})^{2}\right]^{2}$, respectively, where the central values are $\mathrm{n}_{\mathrm{e}}(0)=$ $4 \times 10^{13} \mathrm{~cm}^{-3}$ and $\mathrm{T}_{\mathrm{e}}(0)=1 \mathrm{keV}$, and the plasma radius is $\mathrm{a}=17 \mathrm{~cm}$. The profile of the common ion temperature has the same form as that of the electron density with a central value $T(0)=300 \mathrm{eV}$, To eliminate numerical problems associated with vanishing densities and temperatures at $\mathrm{r}=17 \mathrm{~cm}$, we calculate only for $0 \leqslant \mathrm{r} \leqslant 16.5 \mathrm{~cm}$. The results are relatively insensitive to the exact value of the upper limit at which 
the calculation is cut off; we obtain similar results calculating for $0 \leqslant \mathrm{r} \leqslant 16 \mathrm{~cm}$. The toroidal magnetic field is $\mathrm{B}_{\mathrm{T}}=1.3 \mathrm{~T}$, and the toroidal current is $I_{p}=70 \mathrm{kA}$. The value for $Z_{\text {eff }}$ at the plasma center was taken to be $\sim 5$ [8] and was assumed to be attributable primarily to the oxygen impurity.

\subsection{AND VII PROFILES}

As an initial condtion, oxygen is distributed as 0 VI proportional to the electron density. The uxygen ie distilbuced as 0 VI because we have found that the distribution at the time of the experimental measurements, $10^{-2} \mathrm{~s} \leqslant \mathrm{t} \leqslant 3 \times 10^{-1} \mathrm{~s}$, 1s insensitive to the initial ionization state, provided it is the same or lower than the states of interest, and we can save computer time by not following the evolution from lower states. The oxygen density was taken to be $5 \%$ of the local electron density, which results in $z_{\text {eff }}$ of $\sim 5$ at the center, c.f. Fig. 1 . To describe the subsequent evolutinn of the uxyyen charge states, including that from the neutral oxygen source when it is used, ionization rate coefficients $S_{0}^{k}$ as per Lotz [14] were employed along with his values [15] fur the ionization potentlals. On the basis of gume cumparisuns of Kunze [16,17], we halved Lotz's [1] ionization rate coeflicients for the first six ionization stages, O I through OVI. For oxygen recombination rate coefficients, includillg dielectronic recombination, we followed Breton et al. [18]. In Fig. 1, typical. calculated profiles of $\mathrm{n}_{\mathrm{H}}, \mathrm{Z}_{\text {eff }}$, and the safety factor, $q$, are given along with the input profiles of $\mathrm{n}_{\mathrm{e}}, \mathrm{T}_{\mathrm{e}}$, and $\mathrm{T}$.

In Figs. 2, 3, and 4 we compare 0 VII relative density profiles calculated under different diffusion and neutral oxygen source assumptions 
with a profile inferred from Abel-inverted experimental radial scans of the 0 VII 120.3- $\AA$ photon flux. In Fig. 2, the dotted curve represents purely neoclassical transport, $\alpha=1$ and $\beta=0$ in Eq. (17), using the approximate coefficients of Eqs (7) and no neutral influx. The peak of this curve nearly coincides with that of the experimental curve, but the calculated profile is much broader. The location of the peak of the calculated curve can be estimated by comparing the ionization time and diffusion velocity of 0 VII. The ionization time of 0 VII to 0 VIII varies rapidly in the vicinity of $r=10 \mathrm{~cm}$ in this plasma. It is about $0.0008 \mathrm{~s}$ at $\mathrm{r}=8 \mathrm{~cm}$ and ten times longer at $\mathrm{r}=12 \mathrm{~cm}$. The diffusion velocity, however, is relatively constant in this region at $1-2 \times 10^{3} \mathrm{~cm} / \mathrm{s}$. Thus, 0 VII in the region $\mathrm{r} \leqslant 8 \mathrm{~cm}$ is quickly ionized, but 0 VII in the region $\mathrm{r} \gtrsim 12 \mathrm{~cm}$ penetrates several $\mathrm{cm}$ before ionizing. The combination of these two effects should lead to an O VII density maximum of $r \approx$ 9-10 cm, which agrees with Fig. 2 .

To investigate whether oxygen-oxygen interactions are more important than oxygen-proton in determining the width of the 0 VII density profile and the location of its peak, we recalculated the previous case with oxygen-oxygen interactions deliberately switched off. The profile obtained is the dashed curve in Fig. 2. The whole profile is shifted considerably outward and is much narrower compared with those of the provious case and the experimental profile. To understand these effects let us onmpare the contribution to the O VII particle flux by the O VIIproton interaction with that by the 0 VII-oxygen interactions. Utilizing Eqs (3,7, and 13), neglecting the reduced mass correction of Eq. (14), and for simp1icity, the effects due to temperature gradients, the 0 VIIproton interaction contribution is 
$\Gamma_{\mathrm{OH}}^{6}=\gamma_{\mathrm{O}}^{6}\left(\frac{\mathrm{m}_{\mathrm{H}}}{\mathrm{m}_{\mathrm{O}}}\right)^{1 / 2} \mathrm{C}_{\mathrm{l}}^{*}\left(\mathrm{z}_{\mathrm{H}}^{*}\right)\left(\tilde{\mathrm{Z}}_{\mathrm{OH}}^{6}{ }^{\partial} \mathrm{r} \ln \mathrm{n}_{\mathrm{H}}-\mathrm{z}_{\mathrm{OH}}^{6}{ }_{\mathrm{r}} \ln \mathrm{n}_{\mathrm{O}}^{6}\right)$

and the 0 VII interaction with all the other charged oxygen species is

$\Gamma_{0}^{6 k}=\left(\frac{\gamma_{0}^{6}}{\sqrt{2}}\right)\left[\sum_{k \neq 6} \tilde{z}_{0}^{6 k_{\partial} \partial_{r}} \ln n_{0}^{k}-\left(\sum_{k \neq 6} z_{0}^{6 k}\right) \partial_{r} \ln n_{0}^{6}\right]$

where

$\gamma_{0}^{6}=\frac{\left(q^{2}+1 / 2\right)\left(\rho_{0}^{6}\right)^{2} n_{0}^{6}}{\tau_{00}^{66}}$

We 1dentify the first terms in Eqs (24 and 25) as diffusion terms; they are independent of the 0 VII density gradient, and the second terms as profile broadening terms; they are proportional to the inverse of the 0 VII density gradient scale length and tend to increase it (decrease its inverse). Because $\sqrt{2} \mathrm{C}_{1}^{*}\left(\mathrm{z}_{\mathrm{H}}^{*}\right)$ is of order unity, we express the ratio of the diffusion term in Eq. (25) to that in Eq. (26) approximately as

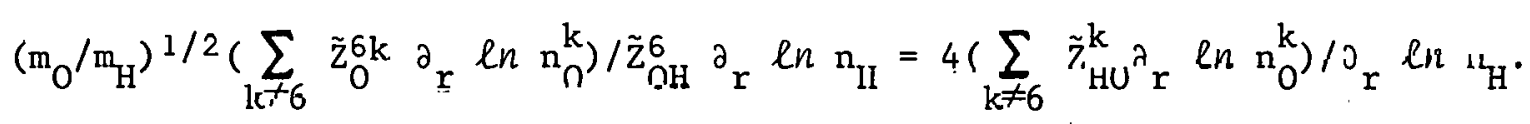
We are interested in the inward diffusion of O VII and, therefore, concentrate on the inner side of its profile. Here the OVII interacts with 0 VIII and $O$ IX as well as with hydrogen. On the innermost portion nf the Inner side of the $O$ VII profile, $4 \sum_{k \neq 6} \tilde{z}_{\mathrm{HO}}^{k} \geq 1$ and the 0 VIII and 0 IX density gradient scale lengths are much shorter than that of hydrogen. Consequently, the oxygen-oxygen interactions will dominate the oxygenhydrogen interaction in determining the inward diffusion of 0 .VII. Where $4 \sum_{k \neq j} z_{H O}^{k} \ll 1$, such as occurs at the edge of the plasma $(j \leqslant 3$ ) and for 0 IX, the oxygen-hydrogen Interaction will dominate. The ratio of the broadening terms is approximately $\left(\frac{m_{0}}{m_{H}}\right)^{1 / 2} \sum_{k \neq 6} z_{0}^{6 k} / z_{O H}^{6} \geq 4\left(z_{\text {eff }}-1\right)$ 
which shows that the oxygen-oxygen interaction also dominates the oxygen-hydrogen interaction in broadening the 0 VII profile, at least when $Z_{\text {eff }} \geq 1$ as it is here.

The results discussed so far were calculated using the simplified. neoclassical coefficients of Eqs (7). The dash-dot curve in Fig. 2 was calculated using the complete coefficients $[5,6]$. The inward diffusion of 0 VII does not progress as far nor, is the profile as broad as when the simplified coefficients are used. The former is not in as good agreement with the experimental results, but the latter is in better agreement. For 0 IX, essentially the same results are obtained with either type of coefficients. This is because the dominant interaction of 0 IX is with protons, and the Lorentz approximation used to derive the nonequal-mass parts of Eqs (7) is reasonably good for a mass ratio of 16 .

From the calculations we find that the 0 IX diffuses outward in the central region of the plasma even for these purely neoclassical cases. It was observed in transport simulations by Dnestrovskii et al. [19] that for impurity concentrations as large as we are considering $\left(\sum_{k} n_{0}^{k}=0.05 n_{e}\right)$ the hydrogen density profile is nearly flat in the central region of the plasma as a result of hydrogen-oxygen interactions. This is cunfirmcd in Fig. 1, and we ascribe this flattening to the combination of outward diffusion of the hydrogen accompanied by a profile broadening both inward and outward. As a cunsequence, the $n$ IX diffuses outward by the profile broadening effecL and rccombines slowly to lower charge states counteracting, to some extent, the loss of $O$ VIII and O VII due to ionization. However, the recombination time is relatively long, $20.02 \mathrm{~s}$, even in the cold edge of the plasma, and so, the 0 VIl density will continue to decrease unless it is resupplied from successive ionizations of a neutral oxygen influx. 
In Figs 3 and 4 we compare $O$ VI relative density profiles calculated under different diffusion and neutral oxygen source assumptions with an 0 VI profile inferred from Abe1-inverted experimental radial scans of the 0 VI $1031.91-\AA$ photon $f 1 u x$. We do not present results from purely neoclassical, sourceless calculations of the 0 VI profile because they disagree too much with the experimental profiles in terms of peak location, profile width, and persistence of a quasi-steady state. The ionisation time in the vicinity of the peak of the experimental profile, $r \approx 12 \mathrm{rm} ;$ sf. Fig. $J(\mathrm{H})$, is so ohort, $u 10^{-1 /} \mathrm{s}$, that to maintaln a quasisteady state 0 VI must be supplied from the ionization of lower charge states. Therefore, we introduce a neutral oxygen influx $\psi_{0}=1.4 \times$ $10^{13} / \mathrm{cm}^{3} \mathrm{~s}$ at $\mathrm{r}=16.5 \mathrm{~cm}$ with a neutral energy of $10 \mathrm{eV}$. The magnitude of the flux yields a line-averaged intensity for the 0 VI transition of $10^{15}$ photons $/ \mathrm{cm}^{2}-\mathrm{sr}-\mathrm{s}$ which is on the order of the intensity measurcd in other ATC experiments [20], and increases the total number of oxygen ions present at $0.029 \mathrm{~s}$ by only about $15 \%$ over that present without the vource. The high neutral energy of $10 \mathrm{eV}$ (compared, e.g., to the wall temperature) is needed to provide sufficiently deep penetration into the plasma to account for the radial Inration of the experimental $O \mathrm{VI}$ profile. The profiles of O VII, $O$ VIII, and $O$ IX are relatively insensitive to the choice of neutral energy, however.

riuflles calculaced with this neutral oxygen influx and the approximate neoclassical coefficients are given as the dotted curves in Fig. 3(a) for $O V I$ and Fig. 3(b) for O VII. Tt is eccn frum F1g. 3(a) that the location of the calculated $O$ VI profile peak and the characteristics of the outer part of the calculated profile are in reasonable agreement 
with the experimental profile. However, the width of the calculated profile is appreciably narrower than the experimental. When we use the full value of Lotz's ionization coefficient for O VI rather than dividing it by two, the profile becomes much narrower. Comparing Figs 2 and 3(b) we see that the presence of the neutral oxygen source causes the 0 VII profile peak to shift outward and the profile to narrow. Both of these effects result from the enhancement of the 0 VII density in the colder region of the plasma by ionization from a greater density of 0 VI than would exist without the neutral source. The narrowing of the profile is in better agreement with experiment, but the outward shift of the peak is in worse agreement. In order to investigate the effect of the magnitudes of the diffusion coefficients, we arbitrarily multiplied them by two and obtained the dashed curves in Fig. 3(a) for O VI and Fig. 3(b) for O VII. While this improves the agreement between calculated and experimental profiles for 0 VI especially in regard to the profile width, the already too broad calculated profile of 0 VII is broadened even more, although the peak is moved closer to the experimental peak. Since we feel constrained to apply such ad hoc prescriptions uniformly to all species, these results only underline the complexity of the situation.

We now consider the effects of anomalous diffusion of oxygen according to Eqs (17 and 18). For these calculations the total oxygen content was maintulued congtant in time via the recycling model of Eq. (23) with $\gamma=1$ and $\psi_{0}=0$. Two cases were çalculated, one with a combination of the approximate neoclassical coefficients and the pseudoclassical coefficient $[\alpha=1, \beta=1$ in Eq. (17)], and one with the purely pseudoclassical coefficient. $(\alpha=0, \beta=1)$. In the former the neutral oxygen influx is 
$2.6 \times 10^{13} / \mathrm{cm}^{3} \mathrm{~s}$ and in the latter, $2.2 \times 10^{14} / \mathrm{cm}^{3} \mathrm{~s}$. The results for the first case are given as the dotted curves in Fig. 4(a) for O VI and in Fig. 4(b) for O VII. Comparing Figs $3(a)$ and $4(a)$ we see that the calculated O VI profile is broadened which is in better agreement with experiment, but we note significant broadening toward the outside. Comparison of Figs $3(\mathrm{~b})$ and $4(\mathrm{~b})$ shows that the calculated 0 VII profile is slightly broadened at the base and the location of the peak has been sliifted toward the outside. This shift and the broadening of the profiles toward the outside are primarily conseyutults of a difference between the neutral influxes for Fig. 3 and Fig. 4, because we obtain nearly the same profiles (especially for $O$ VII) if we calculate using purely neoclassical coefficients and a $\psi_{0}=2.6 \times 10^{13} / \mathrm{cm}^{3} \mathrm{~s}(\gamma=0)$. The results of the calculations with pure pseudoclassical diffusion $(\alpha=0, \beta=1)$ are given as the dashed curves in Fig. 4(a) for O VI and in Fig. 4(b) for O VII. In both cases the profiles are narrowed and shifted outward. Except for the width of the 0 VII profile, tho agreemenl with the experimental profiles is worsened. Comparing Figs 2 and $4(\mathrm{~b})$ we see that purely pseudoclassical diffusion and neoclassical diffusion, excluding the oxygen-oxygen interaction, yield very similar results for 0 VII, which is not entirely unexpected because the purely pseudoclassical diffusion also excludes the oxygen-oxygen interaction.

\subsection{Fe XV Profile}

In the calculations of the Fe XV relative density profilcs, the oxygen is initially distributed as in the calculations described above, and the iron is initially distributed as Fe VI also proportional to the 
electron density. The iron density was taken to be $1 \%$ of the local oxygen density, which is not inconsistent with experimental measurements in ATC [20]. As was the case for oxygen, the iron is distributed as Fe VI to save computation time, and the calculations are insensitive to the exact initial ionization state. For iron we used the ionization rate coefficients of Lotz [21] and his ionization potentials [7]. For recombination rate cnefficients, including dielectronic recombination, we used Jordan's values [22].

In Fig. 5 we compare $\mathrm{Fe} X \mathrm{XV}$ relative density profiles calculated under different diffusion assumptions with a profile inferred from Abelinverted radial scans of the Fe XV 284.2- $\AA$ photon flux. The dotted curve was calculated using the approximate neoclassical coefficients for both iron and oxygen and no neutral iron or oxygen influx. The agreement between the computed and measured profiles is remarkably good for both the location of the peak position and the breadth of the profile. Addition of a neutral iron influx of $8 \times 10^{11} / \mathrm{cm}^{3} \mathrm{~s}$, which doubles the number density of the iron, does not appreciably alter the results. This is in contrast to the results for $O$ VI and $O$ VII which are sensitive to the neutral oxygen influx. We point out that the dominant interaction is the iron-oxygen interaction, and that iron-iron interactions are negligible. We also observe, as was the case for 0 IX, that the higher ionfzalion stagcc $\mathrm{Fe} \mathrm{XX}$ to $\mathrm{Fe} \mathrm{XXV}$ encountered in the calculations and fuund to be peaked at the plasma center tend to diffuse outward by the profile spreading effect. The recombination times of these states in the cooler outer plasma are relatively short, $10^{-4} \mathrm{~s}$ to $10^{-3} \mathrm{~s}$. Thus, a bype of internal recycling of the 1ron impurity is possible in which 
the lower ionization stages move inward and are ionized in the hotter inner plasma, while the higher ionization stages move outward and are recombined in the cooler outer plasma. The dashed curve in Fig. 5 is the result for the combined neoclassical-pseudoclassical diffusion coefficients $(\alpha=1, \beta=1$ ) for both iron and oxygen and for complete recycling of the oxygen $\left(\gamma=1, \psi_{0}=0\right)$. For iron, the neoclassical inward diffusion in the plasma edge region overcomes the outward anomalous diffusion, and no neutral iron source is required to maintain the iron content. Comparing the rotted and daslied i:lurves, it is tempting to conclude that purely neoclassical diffusion is favored to explain the Fe XV measurement. However, considering both theoretical and experimental uncertainties, including the lack of absolute intensity measurements, the possibility that anomalous diffusion coexists with neoclassical diffusion cannot be excluded because the curves differ only slightly. Furthermore, we recall that a purely neoclassical model without a source was inadequate to explain the experimental O VI profila. The dasli-dul curve in Fig. 5 was calculated assuming purely pseudoclassical diffusion and complete recycling of both iron and oxygen. The disagreement of this profile with the experimental profile is not unexpected, considering the resulls ubtained for $O V I$ and $O V I I$.

\section{CUNNCLUSIONS}

In this study of impurity transport in the ATC tokamak, we have considered the effects of the impurity diffusinn model, neutad sources and recycling, and, to a lesser extent, atomic physics rate coefficients. 
Although we have not done so, we could have arbitrarily manipulated the various parameters to obtain agreement between calculation and experiment for the different relative density profiles, but it is not probable that we could have found a single, uniformly applicable prescription that would have simultaneously produced agreement for $O \mathrm{VI}, \mathrm{OVII}$, and $\mathrm{Fe} \mathrm{XV}$. It is clear, however, that it is difficult to separate the diffusion, source, and rate coefficient problems in trying to make detailed comparisons with experiments if the relevant data is scattered among different experiments, e.g., the absolute intensity measurements come from different experiments than the radial profile measurements, or there are no data at all, as when the neutral impurity energy (or range of energies) has not been measured. It is expected that new information from tokamaks such as ISX, PLT, and TFR will make resolution of problems such as these easier in the future.

We also note that the O VI, O VII, and Fe XV profiles studied are localized in the outer half of the plasma and, consequently, are probably insensitive to the transport processes occurring in the inner half of the plasma. The analysis of impurity transport in the inner hotter core region of the plasma will thus depend on measurements of higher ionization impurities than we have considered.

\section{ACKNOWT.EDGMENTS}

This research was sponsored by the office of Fusion Energy (ETM), U.S. Department of Energy under contract W-7405-eng-26 with the Union Carbide Corporation. We thank D. E. Arnurius for programming subroutines to calculate the oxygen and iron rate coefficients. 


\section{REFERENCES}

[1] BURRELL, K.H., Phys. Fluids 19 (1976) 401; ENGELMANN, F., NOCENTINI, A., Nucl. Fusion 17 (1977) 995; HAZELTINE, R.D., WARE, A.A., Phys. Fluids 20 (1977) 1880; MIKHAILOVSKII, A.B., SHUKLMAN, I.G., Sov. J. Plasma Phys. $\underline{3}$ (1977) 278 [Fiz. Plazmy $\underline{3}$ (1977) 495]; SAMAIN, A., WERKHOFF, F., Nucl. Fusion 17 (1977) 53.

[2] BOBROVSKII, G.A., RAZUMOVA, K.A., SANNIKOV, V.V., Sov. J. Plasma Phys. 2 (1976) 499 [Fiz. Plazmy $\underline{2}$ (1976) 898]; Equipe TFR, Nuc1. Fusion 17 (1977) 213; ISLER, R.C., Phys. Rev. Lett. 38 (1977) 1359; Princeton Plasma Physics Laboratory, "Status of Ohmic Heating in PLT," unpublished (Sept. 1977); TERRY, J.L., MARMAR, E.S., CHEN, K.I., MOOS, H.W., Phys. Rev. Lett. 39 (1977) 1615.

[3] OKamoto, M., amano, T., J. Comput. Phys. 26 (1978) 80.

[4] McWHIRTER, R.W.P., in Plasma Diagnostic Techniques, HUDDLESTONE, R.H., and LEONARD, S.L., eds., Academic Press, New York (1965) .

[5] IIIRSHMAN, S.F., Yhys. Fluids 20 (1977) 589.

[6] CRUME, E.C., UCKAN, T., AMANO, T., LEE, D.K., to be published.

[7] RUTHERFORD, P.H., HIRSHMAN, S.P., JENSEN, R., PNST, D.E., SEIDL, F.G.P., in Plasma Wall Interaction (Proc. Int. Symp., Jülich, Oct. 18-22, 1976), Pergamon Press, New York (1977) 173.

[8] COHEN, S.A., CECCHI, J.L., WERNER, E.S., Princeton Plasma Physics Laboratory Report MATT-1248 (June 1976).

[9] JOHNSON, J.L., VON GOELER, S., Phys, Fluids 11 (1969) 255.

[10] POST, D.E., private communication (1977).

[11] YoshIKAWA, S., Phys. Rev. Lett. 25 (1970) 353. 
[12] Equipe TFR, Nuc1. Fusion 17 (1977) 1297.

[13] CECCHI, J.L., Princeton Plasma Physics Laboratory Report MATT-1256 (July 1977).

[14] LOTZ, W., Garching Plasma Physics Institute Report IPP 1/62 (1967).

[15] LOTZ, W., J. Opt. Soc. Am. 58 (1968) 915.

[16] KUNZE, H.J., Space Sci. Rev. 13 (1972) 565.

[17] DOTLA, R.V., BLAHA, M., KUNZE, H.J., Phys. Rev. A-12 (1975) 1076.

[18] BRETON, C., DE MICHELIS, C., MATTIOLI, M., Nucl. Fusion 16 (1976)

891; BRETON, C., DE MICHELIS, C., MATTIOLI, M., EUR-CEA-FC-853, Fontenay-aux-Roses, France (December 1976).

[.19] DNESTROVSKII, Yu.N., INOVENKOV, I.N., KOSTOMAROV, D.P., Nucl. Fusion 16 (1976) 513.

[20] DE MARCO, F., Princeton Plasma Physics Laboratory Report MATT-1012 (November 1973).

[21] LOTZ, W., Garching Plasma Physics Institute Report: IPP 1/76 (February 1968).

[22] JORDAN, C., Mon. Not. R. Astron. Soc. 148 (1970) 17; private communication (1975). 


\section{FIGURE CAPTIONS}

Fig. 1. Radial profiles of electron density, $\mathrm{n}_{e}$, and temperature, $\mathrm{T}_{\mathrm{e}}$, hydrogen density, $\mathrm{n}_{\mathrm{H}}$, common ion temperature, $\mathrm{T}, \mathrm{Z}_{\text {eff }}$, and safety factor, $\mathrm{q}$, at $\mathrm{t}=0.024 \mathrm{~s}$.

Fig. 2. Comparison of experimental o VII profile at $t=0.029 \mathrm{~s}$ (solid curve) with O VII profiles computed with (1) simplified neoclassical coefficients (dotted curve), (2) no oxygen-oxygen interaction and simplified coefficients (dashed curve), and (3) complete neoclassical coefficients (dash-dot curve), no neutral oxygen influx.

Fig. 3. (a) Comparison of experimental o VI profile at $t=0.0295$ (solid curve) with $O$ VI profiles computed assuming a neutral oxygen influx $\psi_{0}=1.4 \times 10^{13} / \mathrm{cm}^{3} \mathrm{~s}$ and (1) simplified neoclassical coefficients (dotted curve) or (2) twice the simplified coefficients (dashed curve). (b) Same as (a) for 0 VII.

Fig. 4. (a) Effect of anomalous diffusion on O VI profile. Solid curve - experimental profile at $t=0.029 \mathrm{~s}$. Dotted curve - computed with sum of simplified neoclassical $(\alpha=1)$ and pseudoclassical $(\beta=1)$ coefficients. Dashed curve - computed with purely pseudoclassical $(\alpha=0, \beta=1)$ coefficients. Complete recycling of oxygen. (b) Same as (a) for 0 VII.

Fig. 5. Comparison of experimental Fe XV profile at $t=0.029 \mathrm{~s}$ (solid curve) with $\mathrm{Fe} \mathrm{XV}$ profiles computed with (1) simplified neoclassical coefficients for both iron and oxygen and no neutral influx (dotted curve), (2) sum of simplified neoclassical. $(\alpha=1)$ and pecudoclassical $(\beta=1)$ coefficients for both iron and oxygen with no neutral iron influx but complete oxygen recycling (dashed curve), and (3) pure pseudoclassical $(\alpha=0, \beta=1$ ) coefficients and complete recycling for both iron and oxygen (dash-dot curve). 
ORNL / DWG/FED-78-301
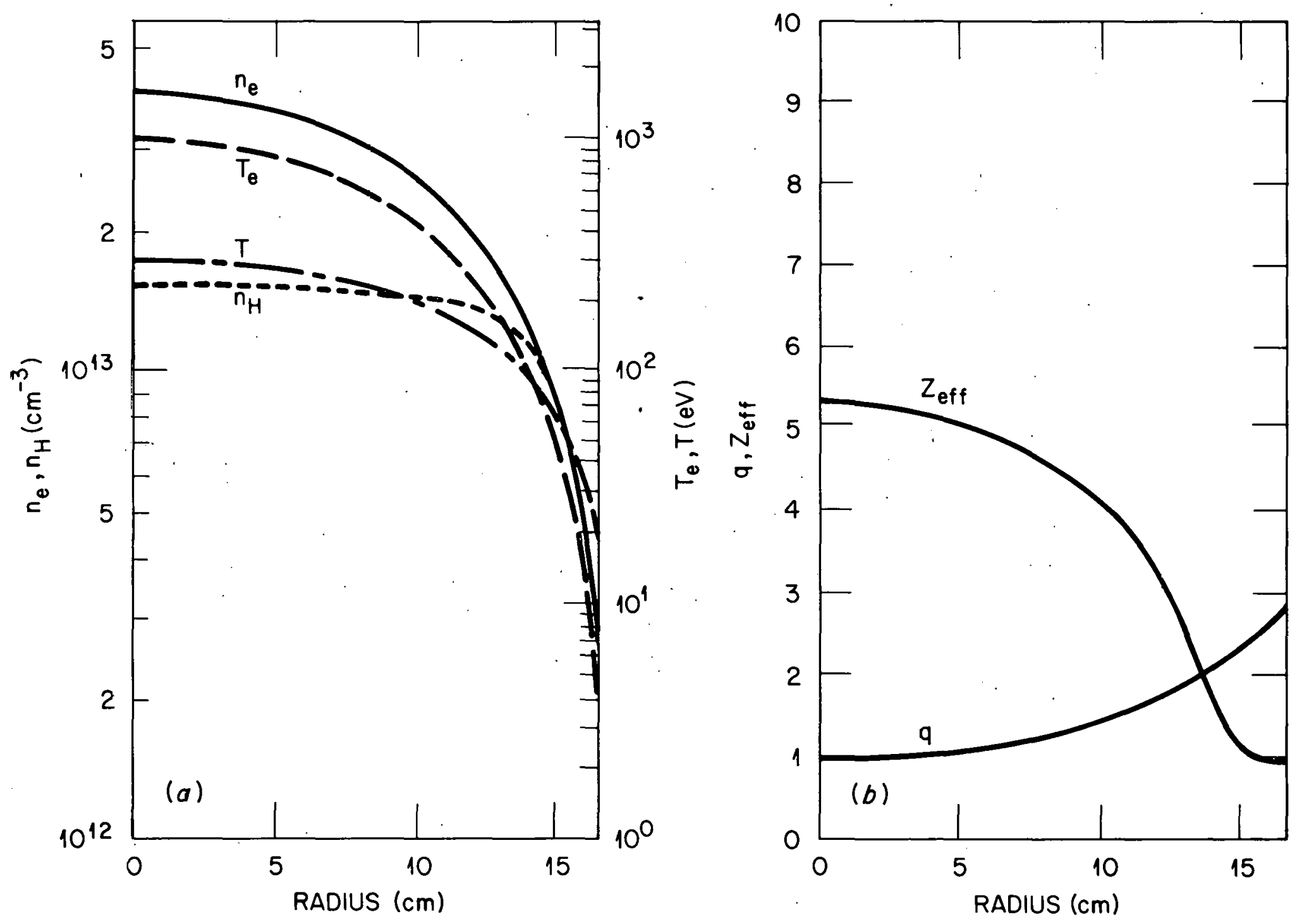

Fig. 1 . 


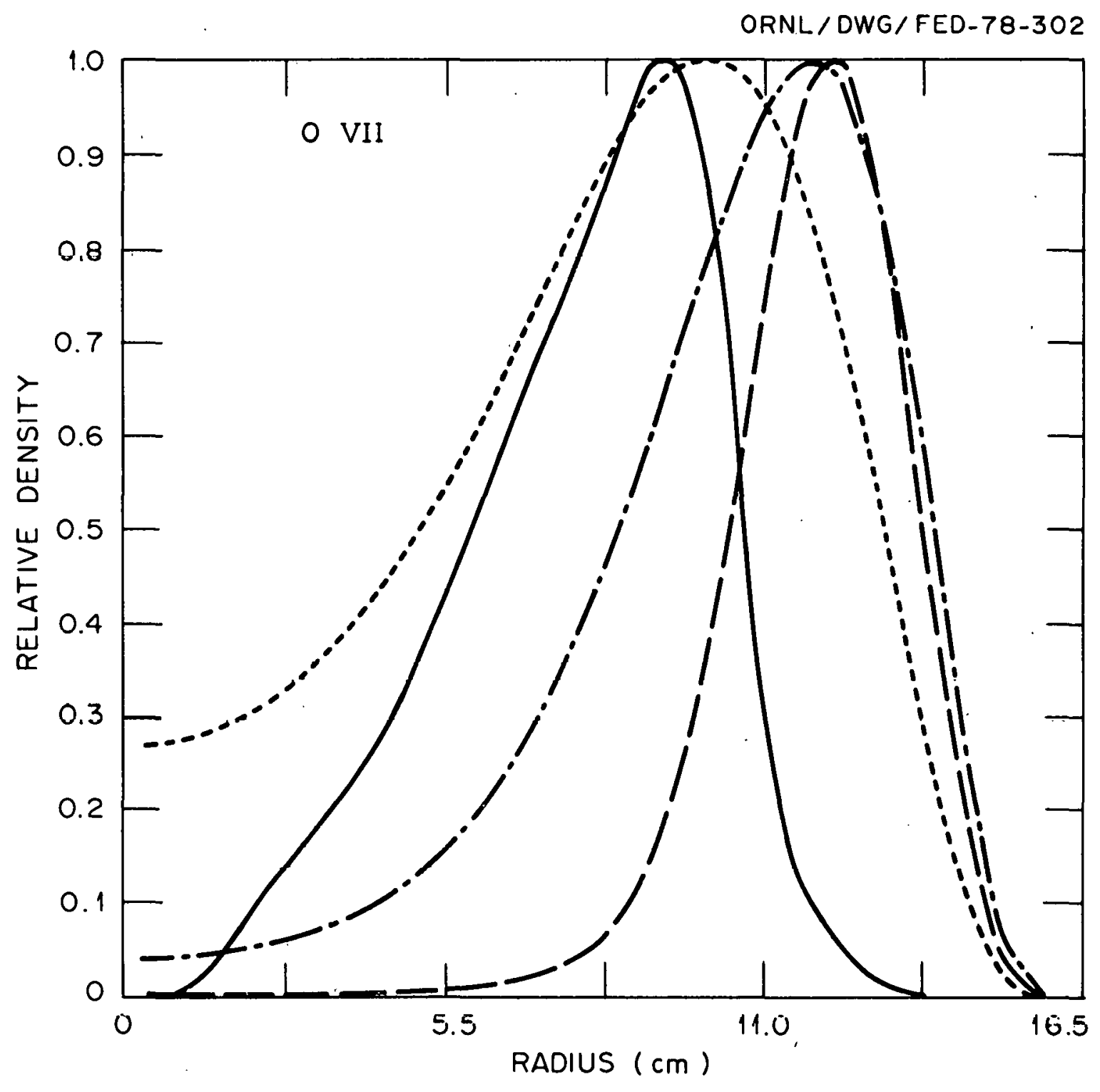

Fig. 2 . 


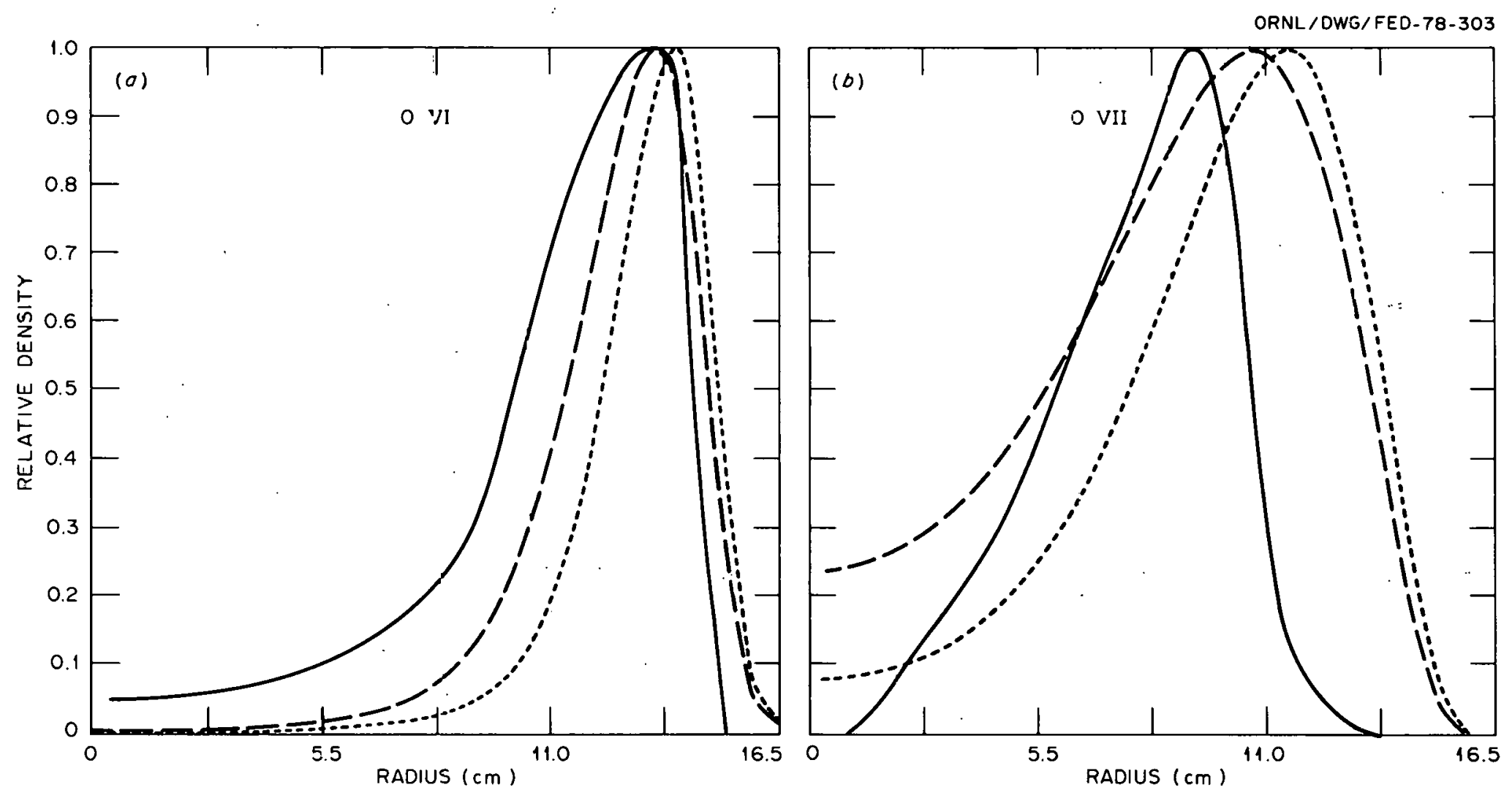

Fig. 3. 


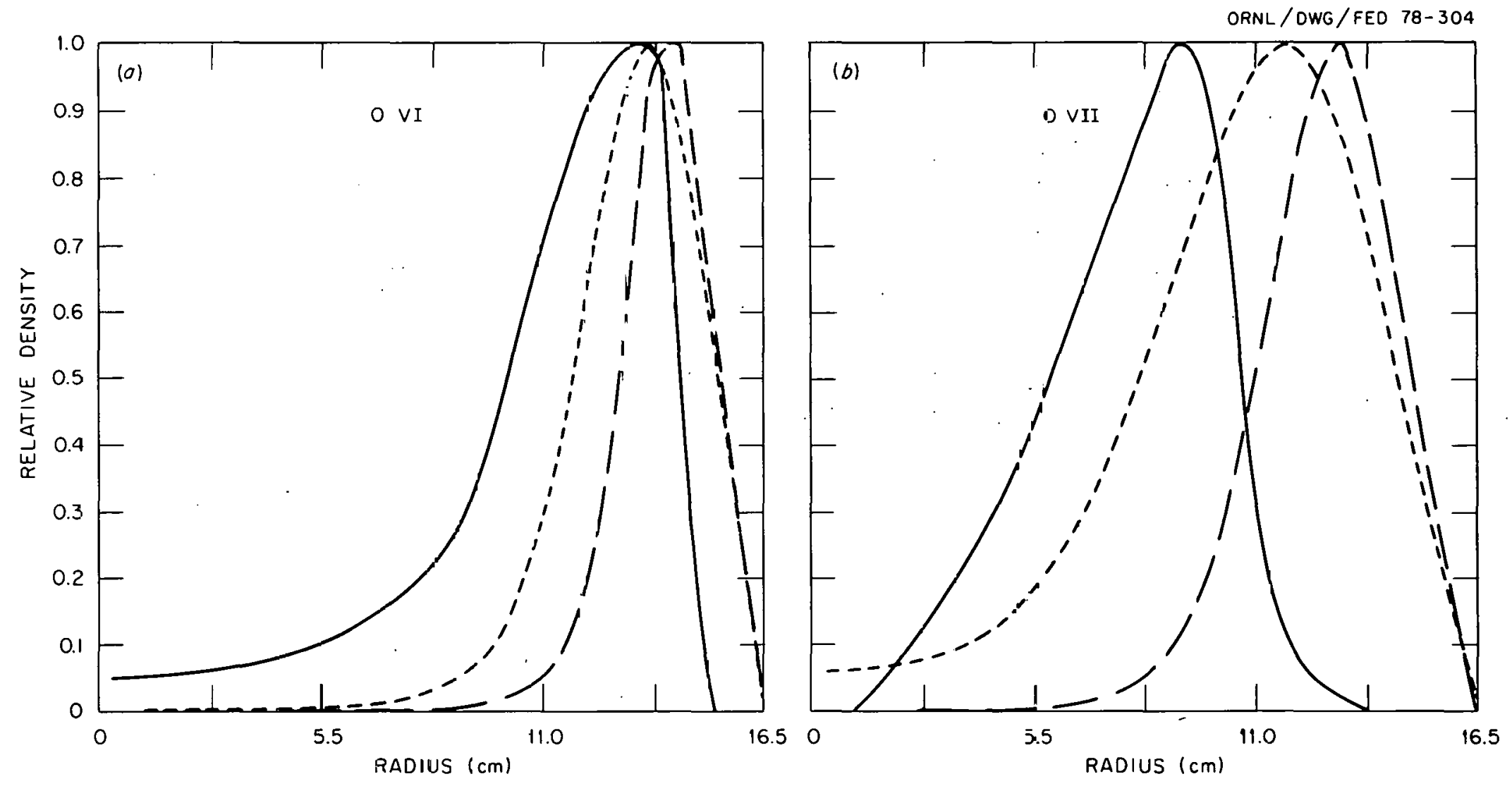

N

Fig. 4. 


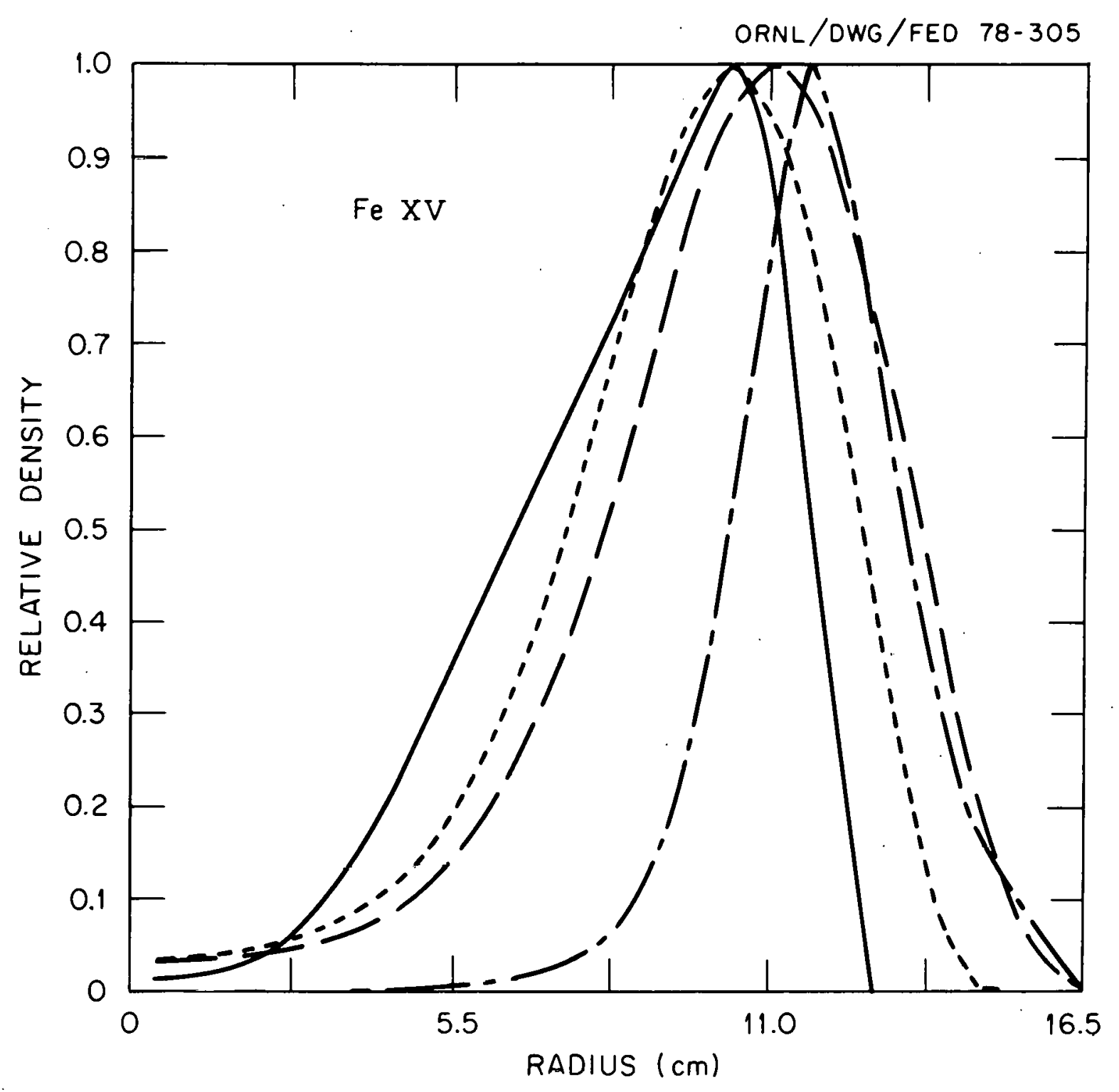

Hig. 5 , 


\section{THIS PAGE}

WAS INTENTIONALLY

LEFT BLANK 
ORNL/TM-6363

Dist. Category UC-20g

\section{INTERNAL DISTRIBUTION}

$\begin{array}{ll}\text { 1. L. A. Berry } \\ \text { 2. J. D. Callen } \\ \text { 3. R. A. Dandl } \\ \text { 4. R. A. Dory } \\ \text { 5. G. G. Kelley } \\ \text { 6. H. H. Haselton } \\ \text { 7. } & \text { P. N. Haubenreich } \\ \text { 8. M. S. Lubell } \\ \text { 9. O. B. Morgan } \\ \text { 10. H. Postma } \\ \text { 11. M. W. Rosenthal } \\ \text { 12. J. Sheffield }\end{array}$

\author{
13. D. Steiner \\ 14-30. T. Amano \\ 31-47. E. C. Crume \\ 48-49. Laboratory Records Department \\ 50. Laboratory Records, ORNL-RC \\ 51. Document Reference Section \\ 52-53. Central Research Library \\ 54. Fusion Energy Division Library \\ 55. Fusion Energy Division \\ Communications Center \\ 56. ORNL Patent Office
}

\section{EXTERNAL DISTRIBUTION}

57. Bibliothek, Max-Planck Institute für Plasmaphysik, 8046 Garching bei München, Federal Republic of Germany

58. Bibliothèque, Service du Confinement des Plasmas, C.E.A., B.P. No. 6, 92, Fontenay-aux Roses (Seine), France

59. Lung Cheung, Department of Electronics, University Science Center, The Chinese University of Hong Kong, Shatin, N.T., Hong Kong

60. J. F. Clarke, Office of Fusion Energy, G-234, Department of Energy, Washington, DC 20545

61. R. W. Conn, Fusion Technology Program, Nuclear Engineering Department, University of Wisconsin, Madison, WI 53706

62. CTR Library, c/o Alan F. Haught, United Technologies Research Laboratory, East Hartford, CT 06108

63. CTR Reading Room, c/o Allan N. Kaufman, Physics Department, University of California, Berkeley, CA 94720

64. J. Nar1 Davidson, School of Nuclear Engineering, Georgia Institute of Technology, Atlanta, GA 30332

65. Documentation S.I.G.N., Départment de la Physique du Plasma et de la Fusion Controlée, Association EURATOM-CEA sur la Fusion, Centre d'Études Nucléaires, B.P. 85, Centre du TRI, 38041. Grenoble, Cedex, France

66. W. R. Ellis, Office of Fusion Energy, G-234, Department of Energy, Washington, DC 20545

67. Harold K. Forsen, Exxon Nuclear Co., Inc., 777 106th Avenue, N.E., C-000777, Bellevue, WA 98009

68. Harold P. Furth, Princeton Plasma Physics Laboratory, Princeton University, Forrestal Campus, P.0. Box 451, Princeton, NJ 08540

69. Roy W. Gould, Callfornla Institute of Technology, Mail Stop 116-81, Pasadena, CA 91125

70. Robert L. Hirsch, Exxon Research and Engineering, P.0. Box 101, Florham Park, NJ 07932 
71. Raymond A. Huse, Manager, Research and Development, Public Service Gas and Electric Company, 80 Park Place, Newark, NJ 07101

72. T. Hsu, Office of Fusion Energy, G-234, Department of Energy, Washington, DC 20545

73. V. E. Ivanov, Physical-Technical Institute of the Ukranian Academy of Sciences, Sukhumi, U.S.S.R.

74. A. Kadish, Office of Fusion Energy, G-234, Department of Energy, Washington, DC 20545

75. L. M. Kovrizhnikh, Lebedev Institute of Physics, Academy of Sciences of the U.S.S.R., Leninsky Prospect 53, Moscow, UI,S.S.R.

76. Guy Laval, Groupe de Physique Théorique, Ecole Polytechinique, 91 Palaiseau, Paris, France

77. Library, Centre de Recherches en Physique des Plasina, 21 Avenue des Rains, 1007, Lausanne, Switzerland

78. Library, Culham Laboracory, United İingdom Atomic Energy Authority, Abingdon, Oxon, OX14 3DB, United Kingdom

79. Library, FOM-Institut voor Plasma - Fysica, Rijnhuizen, Jutphaas, Netherlands

80. Library, Institute for Plasma Physics, Nagoya University, Nagoya, Japan 464

81. Library, International Centre for Theoretical Physics, Trieste, Italy

82. Library, Laboratorio Gas Ionizzati, Frascati, Italy

83. Dsumber G. Lominadze, Academy of Sciences of the Georgian S.S.R., 8 Dzerzhinski St., 38004, Tbilisi, U.S.S.R.

84. Oscar P. Manley, Office of Fusion Energỳ, G-234, Department of Energy, Washington, DC 20545

85. D. G. McAlees, Exxon Nuclear Co., Inc., Research and Technology Laser Enrichment Department, 2955 George Washington Way, Richland, WA 99352

86. J. E. McCune, School of Engineering, Department of Aeronautics and Astronautics, Bldg. 37-391, Massachusetts Institute of Technology, Cambridge, MA 02139

87. Claude Mercier, Service du Theorie des Plasmas, Centre d'Études Nucléaires, Fontenay-aux-Roses (Seine), France

88. K. G. Moses, Office of Fusion Energy, G-234, Department of Energy, Washington, DC 20545

89. D. Pfirsch, Institute for Plasma Physics, 8046 Garching bei München, Federal Republlc of Germany

90. Plasma Physics Croup, Department of Engineering Physics, Australian National University, P.0. Bóx 4, Canberra A.C.T. 2600, Australia

91. Robert E. Price, Office of Fusion Energy, G-234, Department of Energy, Washington, DC 20545

92. A. Rogister, Institute for Plasma Physics, KFA, Postfach 1.913, D-5170, Jülich 1, Federa1 Republic of Germany

93. W. Sadowski, Office of Fusion Energy, G-234, Department of Energy, Washington, DC 20545

94. V. D. Shafranov, I. V. Kurchatov Institute of Atomic Energy, 46 Ulitsa Kurchatova, P.0. Box 3402, Moscow, U.S.S.R. 
95. Yu. S. Sigov, Institute of Applied Mathematics of the U.S.S.R. Academy of Sciences, Miuskaya, Sq. 4, Moscow A-47, U.S.S.R.

96. W. M. Stacey, Jr., School of Nuclear Englneering, Georgla Institute of Technology, Atlanta, GA 30332

97. J. B. Taylor, Culham Laboratory, United Kingdom Atomic Energy Authority, Abingdon, Oxon, OX14 3DB, United Kingdom

98. Thermonuclear Library, Japan Atomic Energy Research Institute, Tokai, Naka, Ibaraki, Japan

99. Francisco Verdaguer, Director, Division of Fusion, Junta de Energia Nuclear, Madrid 3, Spain

100. Director, Research and Technical Support Division, Department of Energy, Oak Ridge Operations, P.O. Box E, Oak Ridge, TN 37830

101-276. Given distribution as shown in TID-4500, Magnetic Fusion Energy (Distribution Category UC-20g, Theoretical Plasma Physics) 